\title{
Profiles of Patients with Musculoskeletal Injury in Children at Tertiary Referral Hospital in Indonesia
}

\author{
Panji Sananta*(D), Rizky Julana, Lasa Dhakka Siahaan (D) \\ Department of Orthopaedic and Traumatology, Faculty of Medicine, Universitas Brawijaya, Saiful Anwar General Hospital, \\ Malang, Indonesia
}

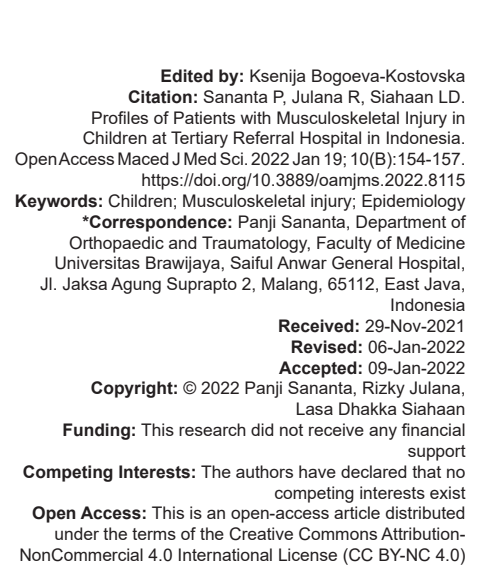

\begin{abstract}
BACKGROUND: Fractures in children cause a long-term disability and decrease quality of life in every person involved. Factors that affect fracture incidence must be identified so that we can create prevention management.

AIM: This study evaluates children's fracture patterns in Saiful Anwar General Hospital Malang from January 2016 to August 2020.

METHODS: A retrospective study was conducted among children under 18 years old by analyzing patients' medical records. The characteristics of patients and fractures are reviewed using SPSS version 25 for Windows.

RESULTS: We analyze 774 children as the sample study, with $70 \%$ of them being boys. Fractures mainly occur in the 12-18 years old group (92.8\%). Most of them are caused by traffic accidents (58\%). Consequently, the street $(76.9 \%)$ is the most frequent place of trauma. Closed fractures $(70 \%)$ are the most common type, and distal radius or ulna $(21.2 \%)$ is the fracture's most frequent site. For treatment, the majority of patients have undergone closed reduction and casting (21.7\%).
\end{abstract}

CONCLUSION: Fractures in children occur predominantly in boys and result from traffic accidents. A single and close fracture is the most common type of fracture.

\section{Introduction}

About $60 \%$ of all fatal traumatic injuries occur in patients younger than 18 years old, and the second most commonly reported type of inpatient pediatric surgery is orthopedic surgery [1]. Trauma has become the leading cause of death in the young population. Every year, approximately, 10 million children are treated for injuries and more than 9000 children die in the United States alone [2]. The 2018 Indonesian Basic Health Research (RISKESDAS) shows the prevalence of trauma in Indonesia is $9.2 \%$, with the highest was in Central Sulawesi (13.8\%), and the lowest was in Jambi (5.4\%). Fall $(40.9 \%)$ and traffic accidents $(40.6 \%)$ are the most common causes of trauma, with the most common age ranges at the time of the accident is 15-24 years old $(11.7 \%)$ and $5-14$ years old $(9.7 \%)$. From fall and traffic accidents trauma, $5.5 \%$ of them experiences fractures. Saiful Anwar General Hospital is located in East Java, where the prevalence of trauma was $9.1 \%$ [3].

The first epidemiological study of fractures in children was carried out in the late $19^{\text {th }}$ century. Beekman and Sulivan in New York and Lichtenberg, Nebraska, performed this research, which included
2'000 cases of fracture in children. The main aim of their study was to develop a fundamental principle for treating pediatric fractures [4]. Landin was a pioneer in the field of pediatric epidemiology research. For 30 years, he studied 8'682 fracture cases in Sweden. Landin investigated the correlation between age, sex, and the environment, varying from one region to another in different countries [5].

This epidemiological analysis can help inform clinicians, researchers, and policymakers about interventions, treatments, and preventive measures of children's trauma. Sweden, Germany, and United States have reduced more than $50 \%$ mortality rate from child injuries by implementing cost-effective prevention strategies [6].

\section{Research Methods}

Our study uses a retrospective collection of pediatric patients under 18 years who presented with fractures to the emergency department of Saiful Anwar General Hospital Malang from January 2016 until 
August 2020. The epidemiological data were collected from the hospital medical records department. The

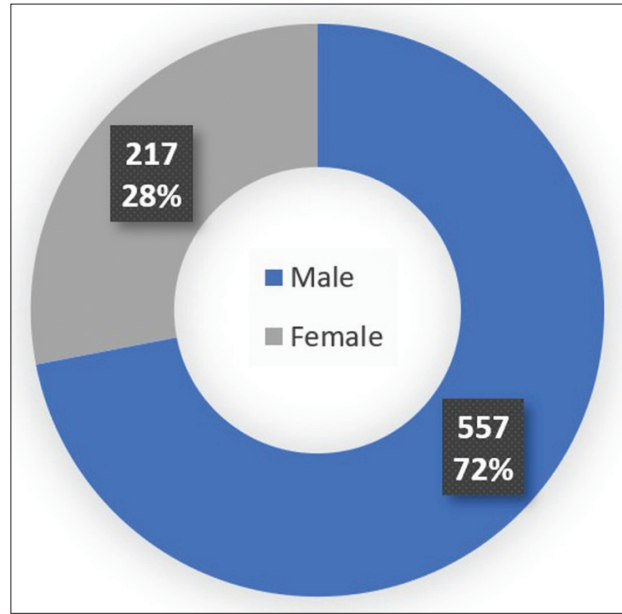

Figure 1: Distribution of samples by gender

data were analyzed using the Statistical Package for the Social Sciences (SPSS version 25.0) IBM, New York, USA. Informed consent was given to all patients and his/her guardians regarding the data obtained in this research which would be submitted for publication.

\section{Results}

Seven hundred seventy-four samples that met the inclusion criteria are obtained. The average age at the time of the incident is 14 years old, with 16 years old being the most common age of incident as many as 94 cases (Figures 1 and 2).

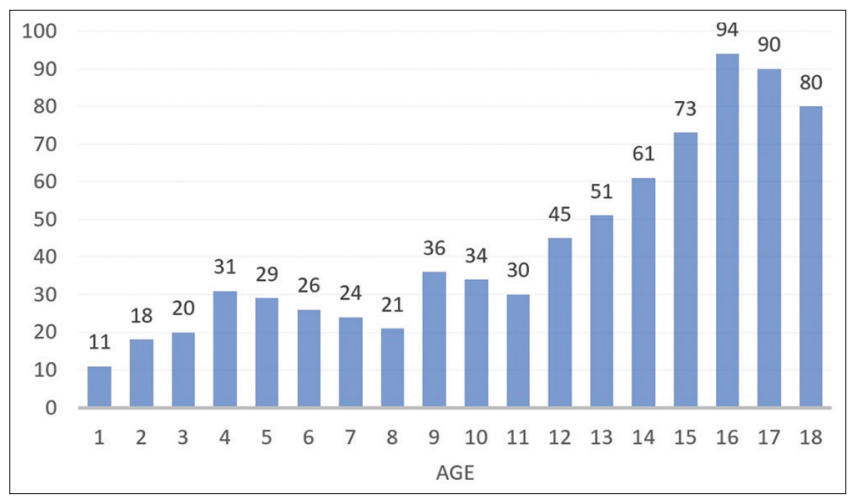

Figure 2: Characteristics of samples by age

The most frequent causes of injury to trauma are traffic accidents $(58 \%)$, followed by fall from a height of more than one meter $(12.66 \%)$, stabbed by sharp objects $(11.11 \%)$, fall from a height of less than one meter $(7.49 \%)$, sports injuries $(6.49 \%)$, and other injuries (3.62\%) (Figure 3).

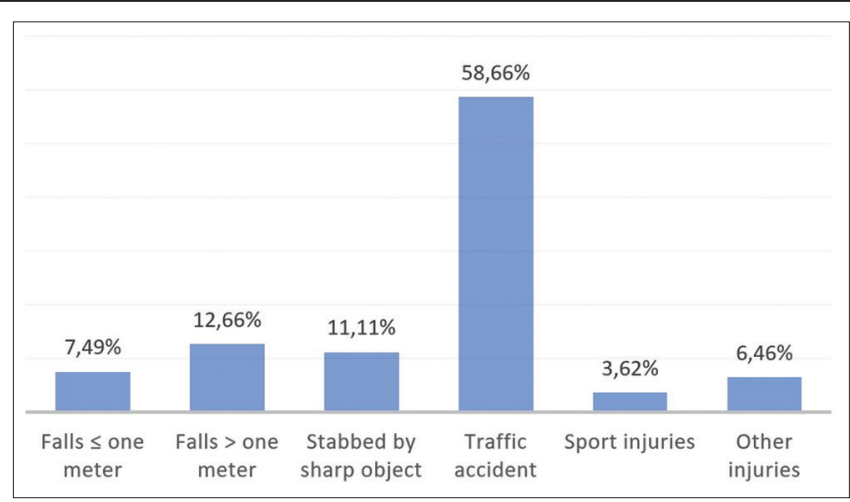

Figure 3: Characteristics of samples by causes of injury

The most common sites of injury are radius or ulna fractures $(21.19 \%)$, followed by laceration or soft-tissue injuries (19.12\%), femur fractures $(16.80 \%)$, humerus fractures $(9.82 \%)$, tibia or fibula fractures $(8.79 \%)$, hand fractures $(8.40 \%)$, foot and ankle fractures $(6.33 \%)$, clavicle fractures $(5.3 \%)$, vertebra fractures $(1.94 \%)$, and pelvic fractures (1.16\%) (Figure 4).

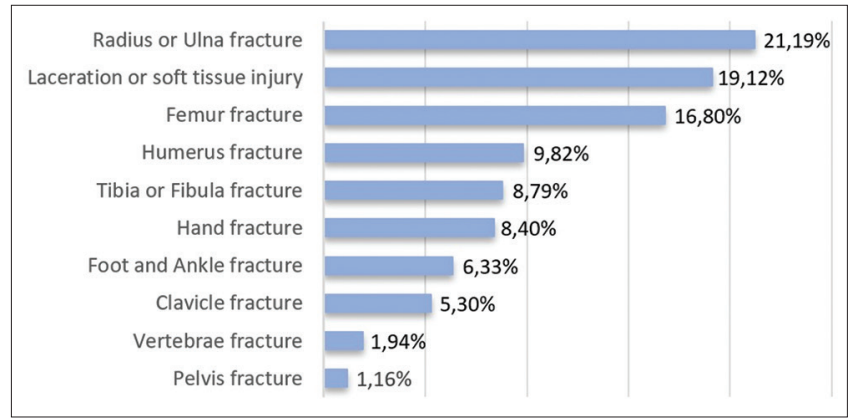

Figure 4: Characteristics of samples by sites of injury

From the data, $69.95 \%$ of the fractures are closed and $30.05 \%$ of the fractures are open. Almost all patients $(95.61 \%)$ seek help to the hospital immediately after experiencing an injury, while the other $3.36 \%$ come after $24 \mathrm{~h}$ and $1.03 \%$ come after complications occur (Figure 5).

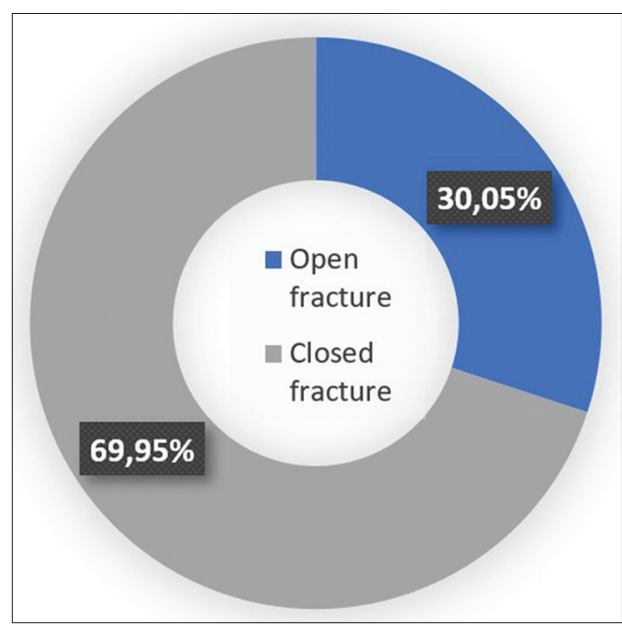

Figure 5: Characteristics of samples by types of fracture

In this study, closed reduction and cast installation were performed by $21.71 \%$, plating $(18.60 \%)$, splint, brace, or sling (13.44\%), ORIF using pin/screw $(5.56 \%)$, closed 
reduction percutaneous pinning $(4.52 \%)$, external fixation $(2.20 \%)$, intramedullary flexible nail $(1.55 \%)$, interlocking nail $(0.90 \%)$, and other procedures $(1.55 \%)$. The remaining $2.07 \%$ of patients refused treatment (Figure 6).

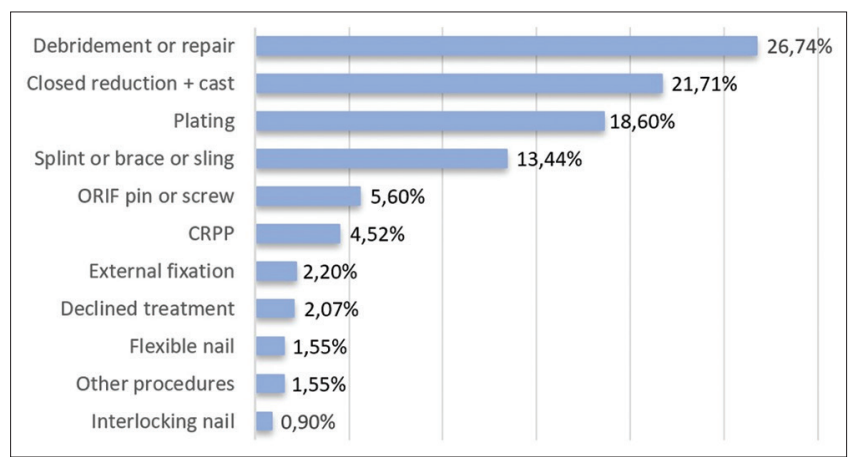

Figure 6: Characteristics of samples by treatment

\section{Discussion}

Injury to children carries a high morbidity and mortality rate due to factors such as physical vulnerability, innate curiosity to experiment, and the inability to perceive danger [7]. Injuries to children can also have significant social and economic implications because children require higher hospital cost, treatment, and material [8].

In this study, boys experienced more fractures than girls. This is consistent with research conducted in other countries such as Sweden, Malaysia, China, and Australia. In Sweden, Malaysia, China, and Australia, the percentages of boys with fractures were $60 \%$, $69.9 \%, 65 \%$, and $60 \%$, respectively [8], [9], [7], [10]. This condition is thought to be mainly due to boys' increased exposure to the risk of injury in their daily activities [11]. Boys tend to be more physically active and use machines/vehicles, so they have a higher risk of trauma or traffic accidents than girls.

This study shows that the average age of children at risk of fracture is 14 years. Research by Song et al. [8] reported the highest incidence of fractures in children in China is 6-12 years old. The peak incidence in Sweden and Australia was 13 years [9], [10], while in Norway; it was 13-15 years [12], which is in line with this study.

The most of the causes of injury in Indonesia are traffic accidents (58\%) caused by the teenagers' behavior who ride motorbikes before 17 years old. This finding corresponds with the 2018 RISKESDAS [12], which states that $38 \%$ of children aged 5-14 years old are riding motorbikes during an accident. These results differ from European countries such as Norway, where the most common cause of fractures in children is sports injuries. Meanwhile, in Sweden and Scotland, the most common cause of fractures in children was fall with a height of $<1 \mathrm{~m}$ [13]. Likewise, China and Malaysia reported that the most common cause of fractures in children was a fall [7], [8].

This study found that the most frequent location of musculoskeletal injuries in children was radius or ulna fractures (21.19\%). Hagino et al. [14] in Japan reported that children under 17 years experienced the most common fractures in the distal radius by $20 \%$. Another study by Song et al. [8] in China also says that children's most common fractures are in the upper extremities. Meanwhile, Bhardwaj et al. concluded that the most common fracture location in children in Malaysia is the elbow, followed by the distal radius and the forearm [7]. In European countries, especially England, Cooper et al. described in their research that fractures in children predominantly occurred in the radius or ulna followed by the hand [5], [9], [15].

In Indonesia, $95.6 \%$ of pediatric patients come directly to a health care center immediately after injury. This finding shows the high trust of the Indonesian people in health services, especially in East Java. This trust relates to the physical or infrastructure support and contact of the medical personnel or professionals of the health service [16].

Our results show that the most common treatment for musculoskeletal injuries in children is debridement and closed reduction followed by cast because the two most common injuries in children are fractures of the radius ulna and soft-tissue injuries. As a result, it is not surprising that debridement and closed reduction followed by cast are the two most common management of injury in this report. In addition, the majority of the fractures were closed fracture instead of open fracture.

This research discusses the condition of musculoskeletal injuries in children to serve as a guideline for prevention, treatment, and further intervention in children musculoskeletal injuries. Further research is needed to provide a broader picture for developing these references.

\section{Conclusion}

Fractures in children occur predominantly in boys and result from traffic accidents. A single and close fracture is the most common type of fracture.

\section{References}

1. Nakaniida A, Sakuraba K, Hurwitz EL. Pediatric orthopaedic injuries requiring hospitalization: Epidemiology and economics. J Orthop Trauma. 2014;28(3):167-72. https://doi.org/10.1097/ BOT.0b013e318299cd20 


\section{PMid:23681411}

2. Sathya C, Alali AS, Wales PW, Scales DC, Karanicolas PJ, Burd RS, et al. Mortality among injured children treated at different trauma center types. JAMA Surg. 2015;150(9):874-81. https://doi.org/10.1001/jamasurg.2015.1121 PMid:26106848

3. Health research and development agency Indonesian Ministry of Health. 2018 Riskesdas Report. J Chem Inf Model. 2018;53:181-222.

4. Beekman F, Sullivan JE. Some observations on fractures of long bones in children. Am J Surg. 1941;51:722-38.

5. Landin LA. Fracture patterns in children: Analysis of 8,682 fractures with special reference to incidence, etiology and secular changes in a Swedish urban population 1950-1979. Acta Orthop. 1983;54:3-109.

\section{PMid:6574687}

6. Oliver J, Avraham J, Frangos S, Tomita S, DiMaggio C. The epidemiology of inpatient pediatric trauma in United States hospitals 2000 to 2011. J Pediatr Surg. 2018;53(4):758-64. https://doi.org/10.1016/j.jpedsurg.2017.04.014

PMid:28506480

7. Bhardwaj A, Sivapathasundaram N, Yusof MF, Sinha NK, Atan AA. Epidemiological characteristics of pediatrics fracture at tertiary care hospital, Malaysia. Int J Contemp Pediatr. 2017;4:1562-6. http://dx.doi.org/10.18203/2349-3291. ijcp20173764

8. Song F, Zeng Y, Tian J, Lv Y, Feng G, Ni X, et al. Epidemiology and the economic burden of pediatric fractures in China: A retrospective study of 14,141 fractures. Bone. 2020;144:115498: https://doi.org/10.1016/j.bone.2020.115498 PMid:32592949

9. Bergman E, Lempesis V, Nilsson JA, Jephsson L, Rosengren BE, Karlsson MK, et al. Time trends in pediatric fractures in a Swedish city from 1950 to 2016. Acta Orthop. 2020;91(5):598-604. https://doi.org/10.1080/17453674.2020.1783484

PMid:32589095

10. Jenkins $M$, Nimphius $S$, Hart $N H$, Chivers $P$, Rantalainen $T$, Rueter $\mathrm{K}$, et al. Appendicular fracture epidemiology of children and adolescents: A 10-year case review in Western Australia (2005 to 2015). Arch Osteoporos. 2018;13(1):63. https://doi. org/10.1007/s11657-018-0478-9

\section{PMid:29860609}

11. Morrongiello BA, Lasenby-Lessard J. Psychological determinants of risk taking by children: An integrative model and implications for interventions. Inj Prev. 2007;13(1):20-5. https:// doi.org/10.1136/ip.2005.011296

\section{PMid:17296684}

12. BrudvikC,HoveLM.ChildhoodfracturesinBergen,Norway:Identifying high-risk groups and activities. J Pediatr Orthop. 2003;23(5):62934. https://doi.org/10.1097/00004694-200309000-00010 PMid:12960626

13. Hedström EM, Svensson $O$, Bergström $U$, Michno $P$. Epidemiology of fractures in children and adolescents: Increased incidence over the past decade: A population-based study from Northern Sweden. Acta Orthop. 2010;81(1):148-53. https://doi. org/10.3109/17453671003628780

PMid:20175744

14. Hagino $\mathrm{H}$. Increasing incidence of distal radius fractures in Japanese children. 2000;5(4):356-60. https://doi.org/10.1007/s007760070043 PMid: 10982684

15. Cooper C, Dennison EM, Leufkens HG, Bishop N, Van Staa TP. Epidemiology of childhood fractures in Britain: A study using the general practice research database. J Bone Miner Res. 2004;19(12):1976-81. https://doi.org/10.1359/JBMR.040902 PMid: 15537440

16. Nawarini A. Peningkatan citra dan kepercayaan masyarakat pada rumah sakit milik. J Manaj Teor Terap. 2012;1:31-44. 